be daunted when he turns to this text. Perhaps he may be forgiven for wondering, in this world teeming with xenobiotics, how any child at all manages to be born and to develop with any semblance of normality. From the research findings cited, the odds would seem to be against this ever happening. The sheer facility with which many of the tests can be executed has its dangers, notably in trying to interpret the expanding host of positive findings to the holistic, human situation. More dangerously, too, isolated discoveries in tissue culture, biochemical mechanisms, developmental carcinogenicity and so on, may easily be lifted out of context by those, maybe. not over-endowed with scientific integrity emotionally then to condemn one, or other, particular agent on the grounds that there is evidence to show that it deforms the foetus, or little children! The constraints in this respect might have been a little more emphasized.

In all, then, this is a book which will be highly informative to the scientific specialist rather than to the general run of medical readers.

R. GouLDING,

Keats' House.

Guy's Hospital.

London SE1 9RT

\section{Examination Notes in Psychiatry}

By Jonathan Bird and Glynn Harrison. Pp. 278. John Wright, PSG Inc., Boston, Bristol and London, 1982. £7.50.

This is an ambitious book, since it claims to be a guide to the content of the Membership Examination of the Royal College of Psychiatrists, and equivalent examinations. The book contains some 25 chapters, with conventional headings such as Schizophrenia, Affective Disorders, Neurotic Disorders, Drug Therapy etc. Each chapter is composed of a series of brief notes in telegrammatic English, very much in the style of lecture notes. They are intended to serve as reminders about something that the reader has previously learned. In addition, at the end of each chapter are a small number of key references. The fact that a significant proportion of these references are from the British Journal of Hospital Medicine indicates that the level of discourse that is attempted is practical rather than academic.

If the book is used in the spirit which the authors intend, i.e. as a way of organizing information already learned, and as a convenient way of revision for somebody who has already done a good deal of ground work, then it will serve a very useful purpose. However, there are two dangers in producing a volume of this nature. First, it may be quite wrongly regarded as a syllabus for the examination of the Royal College of Psychiatrists. The authors make no pretence that this is the case, but naive or unwary postgraduate students may presume this, simply because of its convenience and its comprehensive coverage. Second, it may be regarded by the less industrious as a basic source of information in itself and used as a substitute for a more comprehensive literature. It could thus become a source of lists to be learnt, parrot-fashion, without a proper understanding of the underlying content.

This book will probably be popular with psychiatric trainees for the next year or two, although it may well soon run into the problem of not being up-to-date. Presumably, the authors will provide fairly frequent up-dating of the information. It could well be that clinical tutors will have the main responsibility for ensuring that this book is used by trainees to the best advantage. Examiners in the Membership examination of the Royal College will also, no doubt, be keeping an eye open for the mechanical repetition of lists and phrases found within it.

\section{J. E. COOPER,} Department of Psychiatry. University of Nottingham Medical School.

\section{Human Herpesvirus Infections. Clinical Aspects}

Edited by Ronald Glaser and Tamar Gotlieb-STematsky. Infectious Diseases and Antimiciobial Agents/2. Pp. 280, illustrated. Marcel Dekker, New York, 1982. Sw.Fr.105.00.

Herpes virus infections have been a subject of great interest in recent years and considerable advances have been made in understanding $\frac{\pi}{\mathbb{Q}}$ their pathogenesis and, to some extent, also in their treatment, so this 0 multi-author book about clinical aspects of human herpes virus $C$ infections is timely. It contains 6 reviews by eminent American workers with one chapter on each of the herpes viruses affecting $\vec{P}$ man, with the exception of Epstein-Barr virus which gets 2 chapters;0 and there is a concluding chapter on therapy and prevention.

Each review is comprehensive in its way, but there is variation in $\frac{\bar{\sigma}}{\bar{s}}$ the type of subject matter chosen. Varicella-zoster virus is particu- $\frac{\mathscr{D}}{D}$ larly well covered, but the chapter about herpes simplex infections $\stackrel{\mathbb{Q}}{\varrho}$ shows a considerable bias towards type 2 infection and is weak on type 1 with, for example. little about the major difficulties $\tilde{N}$ surrounding herpes encephalitis. Even the association between $\overrightarrow{0}$ genital infection with type 2 virus and neonatal disease receives only: brief mention.

There is also a slight imbalance in the chapters on Epstein-Barr virus infection with an excellent and highly comprehensive sectionon neurological complications, but little about other clinicalo manifestations. However, there is an authoritative chapter from $\mathrm{G} 3$. and $\mathrm{W}$. Henle on the serology of Epstein-Barr virus infection.

For a book about clinical aspects of these infections, there are very. few illustrations, but this is more than compensated for by the number of references. Overall it is a useful book for postgraduates. and it is relevant to specialists in several different fields.

M. WANSBROUGH-JONES,

St. George's Hospital Medical School London SWI7 0RE.

\section{The Pathogenesis of Infectious Disease}

By C. A. MiMs. 2nd edn. Pp. ix +297 , illustrated. Academic Press, London. 1982. $£ 11.80(\$ 22.00)$.

This is an updating of a well established book. It deals with the enoyct of microorganisms into the body of the host and with the evers which follow: phagocytosis, spread, immune responses, mechanis of cell and tissue damage. culminating in recovery or failure?to eliminate the organism. There are thoughtful sections on microbial strategies in relation to immune responses, on factors influencing susceptibility, and on vaccines.

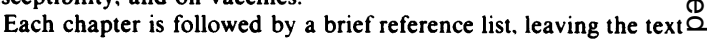
uncluttered. This contributes to the book's great readability, but $\overrightarrow{\vec{T}}$ makes it more difficult to identify the source of some of the 3 statements. That is perhaps not of much consequence in an undergraduate text, but somewhat diminishes its value to trainees in pathology and microbiology. It should still be read by them because of its unfailing interest and its unceasing stream of stimulating ideas. $\bar{\partial}$ If Professor Mims lectures as he writes, his students are very 3 fortunate. This book should be in every medical library.

R. N. GRÚNEBERG,

University College Hospital. London WCIE 6AU.

\section{Recent Advances in Endocrinology and Metabolism}

Edited by J. L. H. O'RIORDaN. Pp. 333, illustrated. Churchill Livingstone. Edinburgh, London, 1982. $£ 18.00$.

It is appropriate that this book is dedicated to Dr John (now Sir John) Nabarro. Physician and Endocrinologist at the Middlesex 0 Hospital (1954-1981), whose valuable contributions to the field of $\mathrm{N}$ clinical endocrinology spanned almost 3 decades. Jeffrey O'Riordan has gathered together a distinguished team of clinicians and basic scientists to outline some of the major recent advances in endocrino- $\sigma$ logy and metabolism. Leslie Rees and R. Smith provide a useful update on the endogenous opiates. a field in which the Barts group have made so many important developments. The chapter by $S . \mathbb{D}$ Bloom and T. Adrian on gut hormones and neuropeptides highlights $\stackrel{\mathcal{S}}{+}$ the major new work in this field. stressing the close relationship of $\square$ these apparently disparate groups of chemical messengers. The complex field of the somatomedins, a new group of tissue growth $\overrightarrow{\mathbb{D}}$ factors, is gradually being clarified. Deborah Doniach and Franco Bottazzo discuss their pioneering work on autoimmunity and the 